\title{
PATTERN OF PRIMARY THYROID MALIGNANCY IN A TERTIARY CARE HOSPITAL
}

\author{
ISLAM MA ${ }^{1}$, ISLAM R ${ }^{2}$, NOOR-E-AS SAYEED AHM ${ }^{3}$, TALUKDER DC ${ }^{4}$, RUMI SK NF ${ }^{5}$, \\ CHOUDHURY AA ${ }^{6}$, FAKIR MAY ${ }^{7}$, SITAN KN ${ }^{8}$
}

\begin{abstract}
:
Background: Among the endocrine malignancies thyroid cancer is the most common. It constitutes a heterogeneous group of malignancies ranking it as the fifth most common cancer worldwide. On health as well as health system it has severe implication. Thyroid cancer incidence is rising most rapidly worldwide. Different thyroid malignancy requires different management strategy. Proper addressing and prompt management of different thyroid malignancies can lessen the suffering.
\end{abstract}

Objective: The study aimed to evaluate the pattern of primary thyroid malignancy in a tertiary care hospital.

Methods: The study was a hospital based descriptive cross sectional study and was conducted in Dhaka Medical College Hospital, Dhaka for one-year period following approval of this protocol. Patients suffering from primary thyroid carcinoma admitted in or attending the outpatient department (OPD) in the department of Otolaryngology and Head-Neck Surgery was approached for inclusion in the study. Written informed consent was taken from the subject and ethical issues were ensured. A total of 50 individual suffering from primary thyroid carcinoma calculated by sample size formula was selected by inclusion and exclusion criteria and data was collected by interview using a semi-structured questionnaire and by personal document analysis. Collected data was analyzed by the SPSS 20 for windows. This study reflects the pattern of primary thyroid malignancy in a tertiary care hospital in Bangladesh.

Results: Mean age of the participants was 32.7 years with $S D \pm 13.8$ years, Minimum age was 17 years and maximum age was 70 years. Majority of the patients (46\%) were in the age group of 3140 years. Among the participants, 70\% were female and 30\% were male. The majority of the patients belong to Dhaka and Rangpur divisions (26\% \& 22\% respectively) of which maximum patients were from rural area (70\%). By occupation, maximum (22\%) of the study subjects were businessman, maximum study subjects were below SSC (24\%) and maximum patients (42\%) had relatively low income per month. Half of the participants had habit of tobacco. All patients (100\%) had presented with palpable thyroid swelling. Among the total participants 54\% had lymphadenopathy, 10\% had dysphagia, $4 \%$ had hoarseness of voice and $4 \%$ had lumpiness in throat. Only $2 \%$ of patients had the symptom of dyspnoea. No palpable lymph nodes were found in $46 \%$ followed by Single node lymphadenopathy 26\%, multiple nodules in one side in $18 \%$, bilateral lymphadenopathy $8 \%$ and $20 \%$ participants had Central compartment lymphadenopathy. USG findings of thyroid revealed Single solid nodule in $22.0 \%$, Single cystic nodule in $16.0 \%$, multiple mixed (solid + cystic) nodules in $62.0 \%$ cases. FNAC findings revealed Anaplastic carcinoma in $2.0 \%$, Follicular neoplasm in $16.0 \%$ and Follicular variant of papillary carcinoma in $8.0 \%$. Papillary carcinoma found in maximum $70.0 \%$ cases. No lymphoma found whereas medullary carcinoma found in $4.0 \%$ cases. Histopathological findings confirmed Anaplastic carcinoma in $4.0 \%$, Follicular carcinoma in $16.0 \%$, Follicular variant of papillary carcinoma in $8.0 \%$ and Papillary carcinoma $68.0 \%$ cases. By histopathological examination no lymphoma found whereas medullary carcinoma found in $4.0 \%$ cases. Only 24\% participants had hypertension and $76 \%$ had DM as co-morbid diseases. Distant metastasis of carcinoma was not present in any of the participants.

Conclusion: In this study, middle age group and female sex prevalent thyroid cancer. Geographical distribution also has an important role. Business, low educational level, low socioeconomic status and tobacco smoking are found the most important risk factors. Histopathologically papillary carcinoma was predominant followed by follicular carcinoma, follicular variant of papillary carcinoma, anaplastic carcinoma and medullary carcinoma. No lymphoma found.

Key words: Primary, Thyroid, Malignancy

J Dhaka Med Coll. 2018; 27(2) : 161-174

1. Dr. Mohammad Asraful Islam, Dept. of Otolaryngology and Head-Neck Surgery, DMCH, Dhaka

2. Dr. Rashedul Islam Dept. of Otolaryngology and Head-Neck Surgery, DMCH, Dhaka

3. Dr. Debnath Talukder, Dept. of Otolaryngology and Head-Neck Surgery, DMCH, Dhaka

4. Dr. A. H. M. Noor-E-As Sayeed, Assistant Professor, Dept. of Otolaryngology and Head-Neck Surgery, DMCH, Dhaka

5. Prof. Dr. SK Nurul Fattah Rumi, Professor, Dept. of Otolaryngology and Head-Neck Surgery, DMCH, Dhaka

6. Prof. Dr. A. Allam Choudhury, Professor, Dept. of Otolaryngology and Head-Neck Surgery, BSMMU, Dhaka

7. Prof. Dr. Md. Abu Yousuf Fakir, Professor \& Head of the Dept. of ENT and Head- Neck Surgery, DMCH, Dhaka

8. Dr. Kazi Noor Sitan, Assistant Professor, Department of Oral and Maxillofacial Surgery, Dental Unit, SSMC, Dhaka Correspondence: Dr. Mohammad Asraful Islam, Dept. of Otolaryngology and Head-Neck Surgery, DMCH, Dhaka, Mobile: 01758439134, E-mail: asrafuleureka@gmail.com 


\section{Introduction}

Thyroid cancer constitutes a heterogeneous group of malignancies which exceeds half a million cases annually, ranking it as the fifth most common cancer worldwide. Head and neck cancers account for $6 \%$ of all cancers worldwide, with nearly 150,000 new cases in Europe alone each year ${ }^{1}$

Although rare; thyroid cancer is the most common malignant disease in endocrine system and is rapidly increasing in incidence ${ }^{2}$. It represents $<1 \%$ of all human tumors and annual incidence of thyroid cancer varies considerably by geographic area, age and $\operatorname{sex}^{3}$. The increasing incidence partially reflects earlier detection of small asymptomatic cancers because of screening in developed countries and improving health-seeking behaviour in developing countries ${ }^{4}$. Different study suggests that most of the thyroid carcinoma show biologically indolent phenotypes ${ }^{5}$ and have an excellent prognosis with survival rates of more than $95 \%$ at 20 years, although recurrence or persistent rate is still significant ${ }^{6}$.

Thyroid cancer has the fastest increasing incidence rate of all cancers in the United States. It is currently the third fastest rising cancer diagnosed in the United States ${ }^{7}$. Incidence rates are notably high among Asians, twice as high among whites as blacks and are slightly higher among non-Hispanic whites than Hispanic whites ${ }^{8}$.

The reported rate of thyroid carcinoma among all malignancies is approximately $1 \%$. In Saudi Arabia, thyroid cancer was the second most common malignancy after breast cancer, while it was reported as the third most common in the United Arab Emirates and fourth most common cancer in Filipino women ${ }^{9}$.

Thyroid cancer is the most common of all endocrine malignancies, accounting for $87 \%$ of all endocrine gland tumors. Clinically diagnosed thyroid cancer accounts for $6.1 \%$ of all newly diagnosed cases of cancer in Saudi Arabia and are ranked fourth in males and second in females ${ }^{10}$.

Thyroid carcinoma is three to four times higher among females than males worldwide and ranking the sixth most common malignancy diagnosed in women ${ }^{11}$. Though it can occur at any age, it is rare in childhood. It is observed that most of the thyroid tumors are diagnosed during third to sixth decades of life ${ }^{11}$.

The incidence rates of thyroid cancer in both women and men have been increasing in recent years ${ }^{12}$.

Patient of thyroid carcinoma may present with various symptoms ranged from simple swelling of neck to trouble swallowing and breathing. They may present with a lump in the neck growing quickly or hoarseness or other voice changes or constant cough that is not due to common cold. Sometimes they may present with pain in the front of the neck, sometimes going up to the ears or others ${ }^{11,13}$. Nevertheless, irrespective of the symptoms, confirmatory diagnosis and management protocol depends on histological diagnosis ${ }^{14}$. Differentiated tumours (papillary or follicular) are highly treatable and usually curable. Poorly differentiated tumours are much less common, are aggressive, metastasise early and have a much poorer prognosis. The thyroid gland may occasionally be the site of other primary tumours, including sarcomas, lymphomas, epidermoid carcinomas and teratomas ${ }^{15}$.

There are a number of histological types that behave differently. Papillary thyroid carcinoma (PTC) is the most common form of thyroid cancer. $70 \%$ of thyroid cancers are papillary. It usually presents between 35 and 40 years of age and is three times more common in women. Most often, it presents as micropapillary thyroid carcinoma $(<1 \mathrm{~cm}$ in size) with an excellent longterm prognosis. Follicular thyroid carcinoma (FTC) is the second most common form of thyroid cancer at about $10 \%$. It is three times more common in women and most often presents between 30 and 60 years of age. Medullary thyroid carcinoma (MTC) arises from the parafollicular calcitonin-producing $\mathrm{C}$ cells of the thyroid and accounts for between $5 \%$ and $8 \%$ of all thyroid malignancies. Thyroid lymphomas are almost always non-Hodgkin's lymphomas, representing $4-10 \%$ of thyroid malignancies. Mainly women aged over 50 are affected and they often have Hashimoto's 
thyroiditis. Hürthle cell carcinoma accounts for about $3-10 \%$ of all differentiated thyroid cancers. They are composed of 75-100\% Hürthle cells. There is a female preponderance. It may present from 20-85 years of age but most often between the ages of 50-60 years. Anaplastic thyroid carcinoma (ATC) is the most aggressive thyroid tumour and one of the most aggressive cancers in humans. The peak incidence is in the sixth to seventh decades (mean age at diagnosis $55-65$ years) and the prevalence is very low $(<2 \% \text { of all thyroid tumours })^{15}$.

Most primary thyroid carcinomas are epithelial in origin and originate from thyroid follicular cells. They arc subdivided into three main pathological types: papillary thyroid carcinoma (PTC), follicular thyroid carcinoma (FTC) and anaplastic thyroid carcinoma (ATC). But medullary thyroid carcinoma (MTC) arises from different source of origin and it comes from thyroid parafollicular (C) cells ${ }^{16,17}$. In some other studies it is shown that among the varieties, PTC consists of $85-90 \%$ of all thyroid cancer cases ${ }^{4}$ and incidence rate is 5.7 per 100,000 person-years in USA with higher incidence rate in women than men $^{3}$. The incidence of follicular thyroid cancer in USA is 0.82 per 100000 person-years whereas it shares $5-10 \%$ of all thyroid cancer. The incidence rates of medullary thyroid cancer (MTC) and anaplastic thyroid cancer (ATC) are 0.11 and 0.21 per 100000 person-years with no noted substantial differences by race, ethnicity and sex, respectively. However, MTC and ATC shares above $2 \%$ and less than $2 \%$ among of all thyroid cancers ${ }^{3,4,18}$. Regarding prognosis of thyroid carcinoma, differentiated thyroid cancer is associated with a 30\% recurrence rate despite initial treatment and in anaplastic carcinoma, which is extremely aggressive, showed almost 100\% diseasespecific mortality ${ }^{4}$. Excellent prognosis is seen in papillary carcinoma of thyroid (PTC) though approximately $10 \%$ of PTC patients undergo recurrences such as lymph node recurrence and lung metastasis ${ }^{4}$. Whereas majority of Follicular carcinoma of thyroid are minimally invasive with slight tumor capsular invasion alone and in case of medullary carcinoma the overall 5year survival of patients is $86 \%$, though older age, advanced stage, the presence of lymph node metastasis at diagnosis were detected as poor prognostic factors ${ }^{4,19}$.

As management of thyroid carcinoma depends on tissue diagnosis and histological evidence ${ }^{20}$ and plan of management differs significantly from different variety ${ }^{19}$; hence, the study is aimed to evaluate the pattern of primary thyroid malignancy in a tertiary care hospital, which will help in early diagnosis and management planning for primary thyroid carcinoma.

\section{Rationale of the research:}

Among thyroid disorders, thyroid carcinoma is an important entity and it has been reported that there is an increasing incidence during the last decades all over the globe ${ }^{21}$. As a result of improved diagnostic accuracy (neck ultrasound and fine needle aspiration cytology) and other imaging techniques, it is attributable to better detection of small papillary carcinomas. Even with increasing incidence, the mortality from thyroid cancer has tended to decline over the last three decades ${ }^{22}$. How much of the decline in mortality is due to better diagnosis rather than to improved treatment of thyroid neoplasm is not clear. The age-adjusted death rate for men and women per year was 0.5 per 100 000, increasing from $0.1 \%$ under age $20 \%-30 \%$ in the seventh and the eighth decades ${ }^{1,21}$. Limited study is available regarding incidence and presentation of primary thyroid malignancy in Bangladesh. A few studies like management of thyroid carcinoma by Alauddin M et al. (2004), histomorphological pattern of thyroid lesion by Rahman MA et al. (2013) ${ }^{23}$ and a review article by Choudhury ABM et al. (2010) are found. However, recent trend of presentation and histological pattern of primary thyroid carcinoma is essential to know that can guide the physicians for early diagnosis and plan a management strategy. For this purpose, the study was designed to explore the pattern of primary thyroid malignancy in a tertiary care hospital in Bangladesh.

\section{Objective}

General:

To describe the clinical presentation of primary thyroid malignancy in a tertiary care hospital 


\section{Specific:}

- To assess the frequency of different clinical presentation of patients suffering from primary thyroid carcinoma

- To evaluate the histological type of primary thyroid carcinoma

- To assess the socio-demographic parameters of the respondents

\section{Materials and Methods}

This descriptive cross sectional study was conducted at the Department of Otolaryngology and Head-Neck Surgery of Dhaka Medical College Hospital January to December 2017, Dhaka to evaluate the histological pattern of primary thyroid carcinoma according to FNAC and histopathology with enrollment of 50 patients suffering from primary thyroid carcinoma attending the OPD and are admitted in department of Otolaryngology and Head-Neck Surgery of Dhaka Medical College Hospital, Dhaka, who are diagnosed either by FNAC or postoperative histopathology by purposive convenient sampling.

\section{a. Inclusion criteria}

- Patient of any age and sex with primary thyroid carcinoma.

- Patients diagnosed as primary thyroid carcinoma either by FNAC or postoperative histopathology.

- Willing to participate in the study

\section{b. Exclusion criteria}

- Follow up case of primary thyroid carcinoma

- Patient with thyroid tumour other than primary thyroid carcinoma

- Seriously ill patient with several comorbid diseases

- Not willing to participate in the study.

\section{c. Operational definition}

Normal ranges of Thyroid Function tests in adults $^{19}$ :

- Free Tri-iodothyronine (FT3): 3.50-8.56 $\mathrm{pmol} / \mathrm{L}$

- Free Thyroxine (FT4): 8.56-25.60 pmol/L

- Thyroid Stimulating Hormone (TSH): 0.3$5.0 \mathrm{mIU} / \mathrm{L}$
Thyroid carcinoma: Lesion in thyroid along with different clinical presentation and evidenced by FNAC or Biopsy

Thyrotoxicosis: Clinical features suggestive of hyperthyroidism \& evidenced by increase FT3, FT4 and decrease TSH

Hypothyroidism: Clinical features suggestive of hypothyroidism \& evidenced by decrease FT3, FT4 and increased TSH

Procedure of data collection and analysis

Written Informed consent was obtained from the patients and/or guardian. Face to face interview was conducted by using a semistructured questionnaire containing items to elicit socio-demographic information (e.g. Age, gender, resident, marital status, occupation, monthly income, level of education etc.) and relevant information about co-morbidity. Information relevant to diagnosis of primary thyroid carcinoma, investigations result and clinical presentation of primary thyroid carcinoma were collected. After collection of all the required data, these was checked, verified for consistency and then tabulated into the computer using the SPSS/PC software' Statistical significance was set as $95 \%$ confidence level at 5\% acceptable error level. Two-sample comparisons of individual characteristics were performed by Student's t- test or chi square test. Differences were considered significant at the $\mathrm{P}<0.05$ level for all these tests. Patients' characteristics were reported as percentages or mean \pm standard deviation. Data was analyzed by the SPSS 20 Windows version and graph $\&$ chart was expressed by using SPSS 20 and MS Excel.

\section{Results}

In this descriptive cross sectional study, 50 patients suffering from primary thyroid carcinoma attending the OPD and are admitted in department of Otolaryngology and HeadNeck Surgery of Dhaka Medical College Hospital, Dhaka, who are diagnosed either by FNAC or postoperative histopathology were included. Results are shown in tables and figures. 
Table-1

Distribution of participants in age groups $(n=50)$

\begin{tabular}{lcc}
\hline Age groups & Frequency & Percent \\
\hline $0-10$ yrs & 0 & 0.0 \\
$11-20$ yrs & 11 & 22.0 \\
$21-30$ yrs & 9 & 18.0 \\
$31-40$ yrs & 23 & 46.0 \\
$41-50$ yrs & 3 & 6.0 \\
$61-70$ yrs & 4 & 8.0 \\
\hline Total & 50 & 100.0 \\
\hline
\end{tabular}

Mean age 32.7 years, $\mathrm{SD}= \pm 13.8$ years, Minimum age 17 years and 70 years.

Mean age of the participants was 32.7 years with SD \pm 13.8 years, Minimum age was 17 years and maximum age was 70 years. Majority of the patients $(46 \%)$ were in the age group of $31-40$ years, followed by $22 \%$ in $11-20$ years, $18 \%$ in $21-30$ years, $8 \%$ in $61-70$ years and $6 \%$ in 41-50 years of age group.

\section{Table-II}

Distribution of participants according to sex $(n=50)$

\begin{tabular}{lcc}
\hline Sex & Frequency & Percent \\
\hline Male & 15 & 30.0 \\
Female & 35 & 70.0 \\
\hline Total & 50 & 100.0 \\
\hline
\end{tabular}

Among the participants, $70 \%$ were female and $30 \%$ were male.

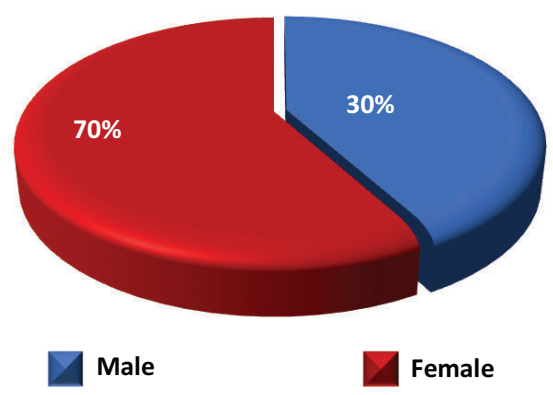

Fig.-1: Distribution of participants according to $\operatorname{sex}(n=50)$.
Table-III

Geographical Distribution of participants $(n=50)$

\begin{tabular}{lcc}
\hline Divisions & Frequency & Percent \\
\hline Dhaka & 13 & 26 \\
Rangpur & 11 & 22 \\
Rajshahi & 7 & 14 \\
Mymensingh & 6 & 12 \\
Barisal & 4 & 8 \\
Khulna & 4 & 8 \\
Chittagong & 3 & 6 \\
Sylhet & 2 & 4 \\
\hline Total & 50 & 100.0 \\
\hline
\end{tabular}

The majority of the patients were from Dhaka and Rangpur divisions (26\% \& 22\% respectively) followed by Rajshahi (14\%), Mymensingh (12\%), Barisal and Khulna (8\%), Chittagong (6\%), Sylhet (4\%).

Table-IV

Distribution of participants according to Residence $(n=50)$

\begin{tabular}{lcc}
\hline Residence & Frequency & Percent \\
\hline Rural & 35 & 70.0 \\
Urban & 15 & 30.0 \\
\hline Total & 50 & 100.0 \\
\hline
\end{tabular}

Maximum patients were from rural area (70\%), whereas $30 \%$ were from urban area.

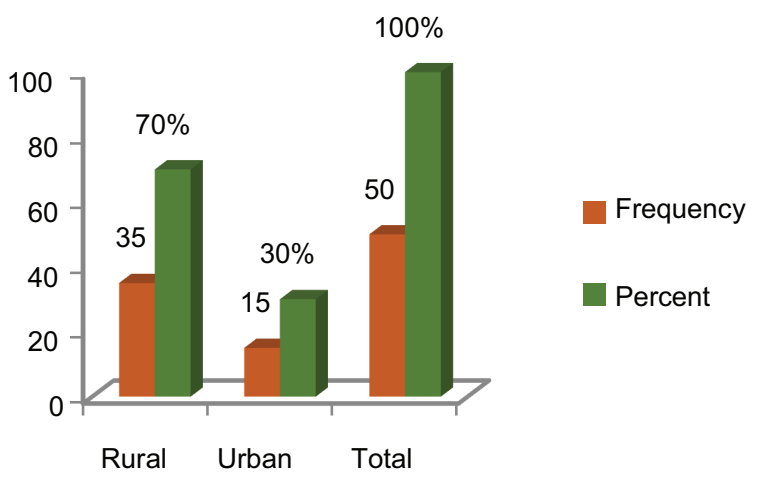

Fig-2: Distribution of participants according to Residence $(n=50)$. 
By occupation, maximum (22\%) of the study subjects were businessman, 20\% were labourer, $16 \%$ government service holders, $14 \%$ were housewife whereas $12 \%$ were from each of farmer and NGO.

Table-V

Distribution of participants according to Occupation $(n=50)$

\begin{tabular}{lcc}
\hline Occupation & Frequency & Percent \\
\hline Govt. Service & 8 & 16.0 \\
NGO service / Private & 6 & 12.0 \\
Businessman & 11 & 22.0 \\
Housewife & 7 & 14.0 \\
Farmer & 6 & 12.0 \\
Labourer & 10 & 20.0 \\
Unemployed & 2 & 4.0 \\
\hline Total & 50 & 100.0 \\
\hline
\end{tabular}

Table-VI

Distribution of participants according to education $(n=50)$

\begin{tabular}{lcc}
\hline Education & Frequency & Percent \\
\hline Illiterate & 6 & 12.0 \\
Below primary level & 7 & 14.0 \\
Below SSC & 12 & 24.0 \\
SSC & 10 & 20.0 \\
HSC & 11 & 22.0 \\
Graduate and above & 4 & 8.0 \\
\hline Total & 50 & 100.0 \\
\hline
\end{tabular}

Maximum study subjects were below SSC (24\%), followed by $22 \%$ of HSC, $20 \%$ of SSC group, $14 \%$ of below primary level and $8 \%$ Graduate and above. On the other hand, $12 \%$ of participants did not go to any school (illiterate).

Table-VII

Distribution of participants according to monthly family income $(n=50)$

\begin{tabular}{lcc}
\hline Income & Frequency & Percent \\
\hline$<15,000 \mathrm{Tk}$ & 6 & 12.0 \\
15,001-25,000Tk & 21 & 42.0 \\
25,001-35,000Tk & 11 & 22.0 \\
35,001-45,000 Tk. & 8 & 16.0 \\
$>45,000 \mathrm{Tk}$ & 4 & 8.0 \\
\hline Total & 50 & 100.0 \\
\hline
\end{tabular}

Only $8 \%$ of the participants had monthly income $>45,000$ Taka, but maximum patients $(42 \%)$ had 15,000-25,000 Taka per month income. Earners between 25,001-35,000 Taka was 22\% and $<15,000$ taka per month were $(12 \%)$.

Table-VIII

Distribution of participants according to personal habits $(n=50)$

\begin{tabular}{lcc}
\hline Habits & Frequency & Percent \\
\hline Betel leafs (Pan) & 20 & 40.0 \\
Tobacco & 25 & 50.0 \\
Alcohol & 3 & 6.0 \\
Others (Like Gul) & 2 & 4.0 \\
\hline Total & 50 & 100.0 \\
\hline
\end{tabular}

Among the participants, $50 \%$ had habit of tobacco, $40 \%$ had used betel leaf i.e. pan, $6 \%$ were alcoholic and $16 \%$ had other habits like use of Gul.

Table-IX

Distribution of participants according to history of previous irradiation $(n=50)$

\begin{tabular}{lcc}
\hline $\begin{array}{l}\text { History of previous } \\
\text { irradiation }\end{array}$ & Frequency & Percent \\
\hline Yes & 2 & 4.0 \\
No & 48 & 96.0 \\
\hline Total & 50 & 100.0 \\
\hline
\end{tabular}

Previous irradiation was received by $4 \%$ patients whereas $96 \%$ patients had no history of irradiation.

Table-X

Distribution of patients according to clinical presentation $(n=50)$

\begin{tabular}{lcc}
\hline Clinical presentation & Frequency & Percent \\
\hline Palpable thyroid swelling & 50 & 100.0 \\
Lymphadenopathy & 27 & 54.0 \\
Dysphagia & 5 & 10.0 \\
Hoarseness of voice & 2 & 4.0 \\
Lumpiness in throat & 2 & 4.0 \\
Dyspnoea & 1 & 2.0 \\
\hline
\end{tabular}


All patients (100\%) had presented with palpable thyroid swelling. Among the total participants $54 \%$ had 1ymphadenopathy, 10\% had dysphagia, $4 \%$ had hoarseness of voice and $4 \%$ had lumpiness in throat. Only $2 \%$ of patients had the symptom of dyspnoea.

Table-XI

Distribution of patients according to lymphadenopathy $(n=50)$

\begin{tabular}{lcc}
\hline $\begin{array}{l}\text { Examination of } \\
\text { lymph nodes }\end{array}$ & Frequency & Percent \\
\hline No palpable lymph nodes & 23 & 46.0 \\
Single node lymphadenopathy & 13 & 26.0 \\
Multiple nodules in one side & 9 & 18.0 \\
(Ipsilateral) & & \\
Bilateral lymphadenopathy & 4 & 8.0 \\
Central compartment & 1 & 2.0 \\
lymphadenopathy & & \\
\hline Total & 50 & 100.0 \\
\hline
\end{tabular}

No palpable lymph nodes were found in 23 (46\%) followed by Single node lymphadenopathy 13 (26\%), Multiple nodules in one side in $9(18 \%)$, Bilateral lymphadenopathy 4 (8\%) and 20\% participants had Central compartment lymphadenopathy.

Table-XII

Distribution of participants according to USG findings of thyroid $(n=50)$

\begin{tabular}{lcc}
\hline USG findings & Frequency & Percent \\
\hline Single solid nodule & 11 & 22.0 \\
Single cystic nodule & 8 & 16.0 \\
Multiple mixed (solid + cystic) & 31 & 62.0 \\
nodules & & \\
\hline Total & 50 & 100.0 \\
\hline
\end{tabular}

USG findings of thyroid revealed Single solid nodule in $11(22.0 \%)$, Single cystic nodule in $8(16.0 \%)$, Multiple mixed (solid + cystic) nodules in $31(62.0 \%)$ cases.

\section{Table-XIII}

Distribution of patients according to FNAC findings $(n=50)$

\begin{tabular}{lcc}
\hline FNAC findings & Frequency & Percent \\
\hline Papillary carcinoma & 35 & 70.0 \\
Follicular neoplasm & 8 & 16.0 \\
Follicular variant of papillary & 4 & 8.0 \\
carcinoma & & \\
Anaplastic carcinoma & 1 & 2.0 \\
Medullary carcinoma & 2 & 4.0 \\
Lymphoma & 0 & 0.0 \\
\hline Total & 50 & 100.0 \\
\hline
\end{tabular}

FNAC findings revealed Anaplastic carcinoma in $1(2.0 \%)$, Follicular neoplasm in $8(16.0 \%)$ and Follicular variant of papillary carcinoma in 4(8.0\%). Papillary carcinoma found in maximum $35(70.0 \%)$ cases. No lymphoma found whereas medullary carcinoma found in $2(4.0 \%)$ cases. Histopathological findings confirmed Anaplastic carcinoma in $2(4.0 \%)$, Follicular carcinoma in $8(16.0 \%)$, Follicular variant of papillary carcinoma in $4(8.0 \%)$ and Papillary carcinoma $34(68.0 \%)$ cases. By histopathological examination no lymphoma found whereas medullary carcinoma found in $2(4.0 \%)$ cases (Table 14).

Only 24\% participants had hypertension and $76 \%$ had DM as co-morbid diseases (Table 15).

\section{Table-XIV}

Distribution of participants according to histopathological findings $(n=50)$

\begin{tabular}{lcc}
\hline Histopathological findings & Frequency & Percent \\
\hline Papillary carcinoma & 34 & 68.0 \\
Follicular carcinoma & 8 & 16.0 \\
Follicular variant of papillary & 4 & 8.0 \\
carcinoma & & \\
Anaplastic carcinoma & 2 & 4.0 \\
Medullary carcinoma & 2 & 4.0 \\
Lymphoma & 0 & 0.0 \\
\hline Total & 50 & 100.0 \\
\hline
\end{tabular}


Table-XV

Co-morbid diseases among the participants $(n=50)$

\begin{tabular}{lcc}
\hline Co-morbid disease & Frequency & Percent \\
\hline Hypertension & 3 & 6.0 \\
DM & 4 & 8.0 \\
Bronchial asthma & 1 & 2.0 \\
Both DM and Hypertension & 2 & 4.0 \\
Both DM and Bronchial & 2 & 4.0 \\
asthma & & \\
\hline Total & 12 & 24.0 \\
\hline
\end{tabular}

Table-XVI

Distribution of participants according to distant metastasis of carcinoma $(n=50)$

\begin{tabular}{lcc}
\hline Metastasis & Frequency & Percent \\
\hline Yes & 0 & 0.0 \\
No & 50 & 100.0 \\
\hline Total & 50 & 100.0 \\
\hline
\end{tabular}

Distant metastasis of carcinoma was not present in any of the participants.

\section{Discussion}

In this descriptive cross sectional study, 50 patients suffering from primary thyroid carcinoma attending the OPD and are admitted in department of Otolaryngology and Head-Neck Surgery of Dhaka Medical College Hospital, Dhaka, who are diagnosed either by FNAC or postoperative histopathology were included.

In the present study, mean age of the participants was 32.7 years with $\mathrm{SD} \pm 13.8$ years, Minimum age was 17 years and maximum age was 70 years. Majority of the patients (46\%) were in the age group of $31-40$ years, followed by $22 \%$ in $11-20$ years, $18 \%$ in $21-30$ years, $8 \%$ in $61-70$ years and $6 \%$ in 41 50 years of age group. Among the participants, $70 \%$ were female and $30 \%$ were male. It was similar in some other studies. In one study done in Saudi Arabia by Fazal Hussain $(2013)^{24}$, the highest incidence of thyroid cancer was between 30-39 years of age and the median age of thyroid cancer patients was 38 years. They mentioned that from 1975 to 2010, patients aged 15-39 years at diagnosis contributed a substantial proportion of thyroid cancers to about $50 \%$ of all thyroid cancer cases. In that study, the highest incidence of thyroid cancer was in the age group of 30-39 years. In comparison, the average age group for developing any cancer in Saudi Arabia was 45-59 years. However, thyroid cancer has struck males and females at a signiûcantly younger age group: between the ages of 35 and 45 years. The median age for thyroid cancer patients in Saudi Arabia is 40 years among females and 44 years among males.

In another study conducted by Marchant $\mathrm{D}$ $(2013)^{25}$, they recruited 55 patients. Of all 31\% $(\mathrm{n}=17)$ were male. The mean age (SD) was 41.8 (15.5) years. Twenty-one (38\%) of participants were in the 31-45 years of age group followed by $15(27 \%) 15-30,11(20 \%)$ in $46-60$ and 8 (14.5\%) in 61-75.

In our study, the majority of the patients were from Dhaka and Rangpur divisions (26\% \& 22\% respectively) followed by Rajshahi (14\%), Mymensingh (12\%), Barisal and Khulna (8\%), Chittagong (6\%), Sylhet (4\%). Maximum patients were from rural area (70\%), whereas $30 \%$ were from urban area.

The geographic variation in the prevalence rate of thyroid cancer could be attributed to the iodine content in food. It has been reported that after the introduction of iodine prophylaxis in various parts of the world, an increase in the relative frequency of papillary carcinoma over follicular carcinoma has been observed ${ }^{26}$.

Goiter is one of the commonest presentations of thyroid disorders in Bangladesh. Prevalence of goiter has been $4-10 \%$ of the general population upon neck examination and up to $50 \%$ of autopsy cases. Biosynthetic defects, iodine deficiency, autoimmune diseases and nodular diseases can each lead to goiter through different mechanisms. Depending on the population studied, Multinodular Goiter (MNG) occurs in up to $12 \%$ of adults. MNG is more common in women than men and increases in prevalence with age. The incidence of goiter in women is 1.2-4.3 times as great as that in men. It is more common in iodine-deficient regions but also occurs in regions of iodine sufficiency, 
reflecting multiple genetic, autoimmune, and environmental influences on the pathogenesis. In a multinodular goiter, nodules grow at varying rates and secrete thyroid hormone 'autonomously', thereby suppressing TSHdependent growth and function in the rest of the gland. Ultimately, complete suppression of TSH occurs in about $25 \%$ of cases, with T 4 and $\mathrm{T} 3$ levels often within the normal range (subclinical thyrotoxicosis) but sometimes elevated (toxic multinodular goiter) ${ }^{23}$.

Ambika Gopalakrishnan Unnikrishnan (2011) ${ }^{28}$ mentioned in his article that recent population studies have shown that about $12 \%$ of adults have a palpable goiter. Autoimmune thyroid disease is probably commoner than iodine deficiency as a cause of goiter in areas that are now iodine sufficient. However, given that iodine deficiency is a problem, the importance of iodine deficiency cannot be underestimated ${ }^{28}$.

The link between endemic goiter and iodine deficiency has been researched in India by several eminent researchers, and this has led to the publication of several important reports ${ }^{29,30,31}$. Critical research has resulted in endemic goiter being reported from all over the country and not just from the Himalayan and Sub-Himalayan regions. Researchers from New Delhi had shown that this was linked to iodine deficiency and that this resulted in decompensated hypothyroidism in many cases. This led to landmark studies which showed that iodine deficiency was associated with hypothyroidism in neonates, setting the scene for the now legendary salt iodization program supported by the Government of India. Subsequent to this program, it was shown that in selected regions of Uttar Pradesh, the prevalence of congenital hypothyroidism had come down from $100 / 1000$ to $18 / 1000^{32}$. Several landmark studies have been carried out in the area of iodine deficiency disorders in the country $29,30,31$.

In the postiodization phase, what happens to the prevalence of goiter? This very important question was answered in an elegantly conducted study ${ }^{33}$. About 14,762 children from all over India were studied for the following characteristics: goiter prevalence, urinary iodine and thiocyanate excretion, functional status of the thyroid, as well as serological and cytopathological markers for thyroid autoimmunity. About $23 \%$ of subjects had a goiter. A significantly higher level of median urinary thiocyanate (USCN) excretion was noted in goitrous subjects $(0.75 \mathrm{mg} / \mathrm{dl})$ when compared with controls $(0.64 \mathrm{mg} / \mathrm{dl} ; \mathrm{P}<0.001)$. The authors suggested that despite iodization, the prevalence of goiter has not dramatically declined $^{33}$. The researchers noted that thyroid autoimmunity could only partly explain the goiter and concluded that the role of goitrogens is an area that deserves further study Unnikrishnan AG (2011). As mentioned by Unnikrishnan AG (2011) a further large scale study should also be done in Bangladesh.

In this study, by occupation, maximum (22\%) of the study subjects were businessman, 20\% were labourer, $16 \%$ government service holders, $14 \%$ were housewife whereas $12 \%$ were from each of farmer and NGO. Maximum study subjects were below SSC (24\%), followed by $22 \%$ of HSC, $20 \%$ of SSC group, $14 \%$ of below primary level and $8 \%$ Graduate and above. On the other hand, $12 \%$ of participants did not go to any school (illiterate). Only $8 \%$ of the participants had monthly income $>45,000$ Taka, but maximum patients (42\%) had 15,00025,000 Taka per month income. Earners between 25,001-35,000 Taka was 22\% and $<15,000$ taka per month were $(12 \%)$. These classifications were done according to the information of Standard Occupational Classification (SOC) Manual, 2018 and Pocket Book 2017, BBS ${ }^{34,35}$.

Of the 462 patients with thyroid cancer, the majority were diagnosed with papillary thyroid cancer $(84.8 \%)$ followed by follicular $(12.1 \%)$, medullary $(2.6 \%)$, anaplastic $(0.2 \%)$, and others $(0.2 \%)$. A total of $214(47.0 \%)$ cases were microcarcinoma (tumor size d" $1 \mathrm{~cm}$ ). Cases were more likely to be women, middle aged, and obese compared to controls. Cases were more likely to be non-drinkers and of lower education compared to controls. A higher proportion of cases than controls reported having a firstdegree relative with thyroid cancer. Distributions of family income, race, and smoking between cases and controls were 
similar. In summary, they observed increased risk of thyroid cancer associated with health diagnosing and treating practitioners, registered nurses, building cleaning and pest control workers, janitors and cleaners, cooks and food preparation workers, retail salesperson, customer service representatives and financial managers. Our finding that healthcare workers experienced an increased risk of papillary microcarcinoma warrants further investigation ${ }^{36}$.

Certain occupational exposures have been linked to the risk of thyroid cancer; however, results have been inconclusive ${ }^{37}$. Occupations involving radiation exposure, such as radiological technologists, are most consistently linked to increased risk of thyroid cancer ${ }^{38,39}$. Other healthcare or medical workers including dentists and dentist assistants, female nurses, pharmacists, and psychologists that may or may not have radiation exposure have been less consistently associated with an increased risk of thyroid cancer. Some studies have reported that farmers and agricultural workers experienced an increased risk of thyroid cancer, others, however, found no association. Studies have inconsistently linked teachers, economists, female bookkeepers, sales-women and stenographers, female textile workers, women worked in video display terminals, administrative staff, firefighters, and clerical workers to thyroid cancer risk ${ }^{38,41}$. Future studies will attempt expand on these analyses, examining specific occupational exposures and risk of thyroid cancer by applying job exposure matrices.

Among the participants of the present study, $50 \%$ had habit of tobacco, $40 \%$ had used betel leaf i.e. pan, $6 \%$ were alcoholic and $16 \%$ had other habits like use of Gul.

Dr. Md Abu Hanif, in an article published in The Daily Star, June 28, 2015, mentioned that Head and neck region cancers include cancers of the lip, oral cavity, tongue, pharynx, larynx, nose with para-nasal sinuses, salivary glands and the neck. The risk factors of developing these cancers are consumption of betel quid, betel nut, jarda, gul, bidi, cigarettes, viral infection, poor oral hygiene, exposure to radiation, industrial fumes, alcohol, chemicals etc. The symptoms are according to the primary site of origin. These are difficulty in taking food, change of voice, respiratory distress, nasal obstruction, bleeding from the nose, swelling in the neck and pain in the different sites of head and neck which starts from above the chest to up to the top of the head. In that article it was mentioned that $3 \%$ of all cancers occur in the thyroid gland and 95\% thyroid cancers have good prognosis after surgery. Thyroid cancers spread quickly in the lymph nodes, lungs and bones. The major challenge for thyroid surgery is saving the recurrent laryngeal nerve which controls the voice and preservation of parathyroid glands which maintains the blood calcium level ${ }^{42}$.

In the current study, previous irradiation was received by $4 \%$ patients whereas $96 \%$ patients had no history of irradiation. But another study shows related findings.

Merchant D (2012) mentioned in his study that none of the patients had history of head and neck irradiation. Among all participants only 2 $(3.6 \%)$ had positive family history of thyroid carcinoma and $2(3.6 \%)$ had history of other endocrine disorder, 1 had hyperthyroidism and 1 had Type 2 Diabetes Mellitus ${ }^{25}$.

In the present study, all patients (100\%) had presented with palpable thyroid swelling. Among the total participants $54 \%$ had lymphadenopathy, $10 \%$ had dysphagia, $4 \%$ had hoarseness of voice and $4 \%$ had lumpiness in throat. Only $2 \%$ of patients had the symptom of dyspnoea. These findings have similarity with other studies.

In one study it was found that the most common presentation of study participants was neck swelling/mass which was present in 54 (98\%) patients followed by weight loss in 34 (62\%). Other sign and symptoms were cervical lymphadenopathy in 28 (51\%), dyspnea in 12 $(22 \%)$, dysphagia in $9(16 \%)$, recent change of voice in $11(20 \%)$, superior vena-caval syndrome and stridor each in $2(3.6 \%)$ patients while none of them presented with paraneoplastic syndrome, other sign and symptoms of metastasis or eye signs ${ }^{25}$. 
Another study showed that all of the patients presented with thyroid gland nodules with infrequent local compressive symptoms such as dysphagia, dyspnea and hoarseness. These symptoms are not specific for malignant diseases and may present in benign conditions or absent in malignant conditions ${ }^{43}$.

In this study, no palpable lymph nodes were found in 23 (46\%) followed by Single node lymphadenopathy 13 (26\%), Multiple nodules in one side in 9 (18\%), Bilateral lymphadenopathy $4(8 \%)$ and $20 \%$ participants had Central compartment lymphadenopathy.

Merchant D (2012) found, the commonest presentation in papillary carcinoma was thyroid swelling (96.93\%). The other presentations were occult thyroid $(3.06 \%)$, cervical $1 \mathrm{ymph}$ metastasis. In follicular carcinoma the presentations were thyroid swelling $(100 \%)$, cervical lymph node metastasis $(6.25 \%)$ and distant metastasis (21.87\%).

USG findings of thyroid revealed single solid nodule in $11(22.0 \%)$, single cystic nodule in $8(16.0 \%)$, multiple mixed (solid + cystic) nodules in $31(62.0 \%)$ cases.

Thyroid nodules are a common occurrence in the general population, and these incidental thyroid nodules are often referred for ultrasound (US) evaluation. US provides a safe and fast method of examination. It is sensitive for the detection of thyroid nodules, and suspicious features can be used to guide further investigation/management decisions.

A thyroid nodule is a discrete lesion within the normal thyroid. Such nodules are a common occurrence in the general population and a frequent incidental finding on computed tomography $(\mathrm{CT})$ and magnetic resonance imaging (MRI). Autopsy studies have reported incidental thyroid nodules in up to $50 \%$ of subjects. Most nodules are benign, but between 3 and $7 \%$ of cases are found to be malignant. Ultrasound (US) has become an important diagnostic tool in the assessment of thyroid nodules. It is highly sensitive for detecting nodules, and the sonographic features of the nodules can be used to determine the need for further investigation. A number of studies have investigated both benign and malignant sonographic features of thyroid nodules. However, because it is unrealistic from an economic and patient anxiety point of view to biopsy every thyroid nodule in order to exclude malignancy, a reliable guideline was necessary to specifically target nodules that require biopsy. Based on current evidence, the British Thyroid Association (BTA) recently produced a US classification (U1-U5) of thyroid nodules to facilitate the decision-making process regarding the need to perform fine-needle aspiration cytology (FNAC) in suspicious/unequivocal cases $^{44}$.

FNAC findings revealed Anaplastic carcinoma in $1(2.0 \%)$, Follicular neoplasm in $8(16.0 \%)$ and Follicular variant of papillary carcinoma in 4(8.0\%). Papillary carcinoma found in maximum $35(70.0 \%)$ cases. No lymphoma found whereas medullary carcinoma found in $2(4.0 \%)$ cases.

The most frequent thyroid cancer found in the study conducted by Merchant D, was papillary thyroid carcinoma $44(80 \%)$ followed by follicular $6(11 \%)$, medullary $2(3.6 \%)$, anaplastic $1(1.8 \%)$ and Hurthle cell carcinoma in $2(3.6 \%)$ patients. Papillary thyroid carcinoma was common in both males and females $12(70.6 \%)$ and $32(84.2 \%)$ respectively followed by follicular and anaplastic carcinoma in females and medullary and hurthle cell carcinoma in males.

Histopathological findings confirmed Anaplastic carcinoma in $2(4.0 \%)$, Follicular carcinoma in $8(16.0 \%)$, Follicular variant of papillary carcinoma in $4(8.0 \%)$ and Papillary carcinoma $34(68.0 \%)$ cases. By histopathological examination no lymphoma found whereas medullary carcinoma found in $2(4.0 \%)$ cases. Our findings can be compared with the findings of some other studies.

Merchant D (2012) found in this study the most frequent thyroid cancer was papillary thyroid carcinoma $44(80 \%)$ followed by follicular 6 (11\%), medullary $2(3.6 \%)$, anaplastic $1(1.8 \%)$ and Hurthle cell carcinoma in $2(3.6 \%)$ patients. He found papillary thyroid carcinoma was common in both males and females $12(70.6 \%)$ and $32(84.2 \%)$ respectively followed by follicular and anaplastic carcinoma in females and medullary and hurthle cell carcinoma in males. 
In that study papillary thyroid carcinoma was the most frequent histological type of thyroid tumor in both males and females and it comprises $80 \%$ of all thyroid malignant tumors which is comparable to our study (68.0\%) and another study done by Champa Sushel et $\mathrm{al}^{45}$ where $73 \%$ of all thyroid carcinomas were papillary thyroid carcinoma. Although it is consistent with several other studies but reports from Nigeria showed that the follicular carcinoma was the most common thyroid cancer whereas in the present study, follicular thyroid carcinoma constitutes $16.0 \%$ which can be compared with the study done by Merchant D $(10.9 \%)$ as well as the study done by Sajid et $\mathrm{al}^{46}$ in which follicular carcinoma was second most common type of thyroid carcinoma constituting $11.6 \%$. This was also shown by the study done in Rawalpindi by Tariq Sarfraz and colleagues but the percentage was higher $23.8 \%$ for follicular thyroid carcinoma. Medullary thyroid carcinoma constitutes $3.6 \%$ compared to the study conducted by Sajid et al. The medullary thyroid carcinoma comprised about $4.0 \%$ in this study in contrast to the study conducted by Merchant D and by Tariq Sarfraz et al. ${ }^{47}$ which showed $1.8 \%$ and $4.8 \%$ respectively of medullary thyroid carcinoma.

Comorbidity may be an important contributory factor to differences in the treatment and outcome of cancer, especially in older patients. It might also provide information on the aetiology of the cancer in cases of high or low frequency. In this present study, co-morbidity was found in only $24 \%$ participants. Among them, 6\% had Hypertension, 8\% had DM, 2\% had Bronchial asthma. Both DM and Hypertension, and DM and Bronchial asthma was found as co-morbid diseases in the same percent $(4 \%)$ of participants. But in study by Kuijpens JL (2006) ${ }^{48}$ comorbidity was present in $32 \%$ of the patients; $23 \%$ had one and $12 \%$ had two or more concomitant diseases. The prevalence of comorbidity increased with age. Hypertension was the most frequent comorbidity (18\%), followed by 'other cancers' $(7 \%)$, cardiovascular diseases $(6 \%)$ and diabetes mellitus (6\%) (Kuijpens JL et al. 2006).

Thyroid cancer may spread to the lymph nodes, lungs, bone and occasionally brain. Sometimes, thyroid cancer is very large and starts growing into structures in the neck, such as the trachea, esophagus, blood vessels, muscles, or nerves. This is considered "locally advanced" thyroid cancer. In this study, metastasis of carcinoma was not present in any of the participants. The findings in some other studies can be mentioned. Thyroid cancer represents a unique biological tumor where even with the high incidence of distant metastases, the overall prognosis is not as poor as many other human cancers. The overall long-term survival in patients presenting initially with distant metastasis is approximately $50 \%$. The overall incidence of distant metastases varies between 10 and $35 \%$, depending upon the histology. It also found that the overall incidence is directly related to various histologies, being least in papillary thyroid carcinoma (10\%) and highest in Hürthle cell tumor (33\%). In patients with medullary and anaplastic thyroid cancer, the incidence of distant metastases is also very high. The incidence of distant metastases at the time of initial presentation in differentiated thyroid cancer is approximately 4\%. In high-risk patients - especially in patients with extrathyroidal extension or massive nodal metastasis, the distant metastases can be evaluated after total thyroidectomy with radioactive iodine ablation. Pulmonary metastases are very common in young individuals, but they are extremely well treated and the mortality from distant metastases in this group is very low. However, distant metastases in patients with poorly-differentiated carcinoma have a poor prognosis. In high-risk patients, generally a total thyroidectomy should be undertaken so that the patient can undergo radioactive iodine dosimetry and ablation as indicated $^{49}$.

\section{Conclusion}

In conclusion of the study, majority of the patients were in the middle age group i.e. 3140 years, prevalence of thyroid cancer was more in female. Geographical distribution also has an important role. The majority of the patients were from Dhaka and Rangpur divisions followed by Rajshahi, Mymensingh, Barisal and Khulna, Chittagong, Sylhet. Maximum of the study subjects were businessman, low 
educational, low socioeconomic status and tobacco smoking are the most important risk factors. Histopathologically Papillary carcinoma was predominant followed by Follicular carcinoma, Follicular variant of papillary carcinoma, Anaplastic carcinoma and medullary carcinoma. No lymphoma found.

\section{Limitation of the study}

- In this study the sample size was small

- This study did not involve multiple centers

- This was a descriptive cross sectional type of study

- More outcome variables might have been included in this study

- The study had time constraints

\section{Recommendation}

- Findings of this study may help the clinicians to be aware in diagnosing and managing thyroid carcinoma

- Further hospital and / or population based study with large sample size should be conducted at multiple centers

- Long cohort study including more outcome variables may be designed

\section{Ethical Implication}

Patients (subjects) and their relatives were clearly informed about the scope and limitations of the study. Informed Written consent was obtained from the patients (subjects). Confidentiality of the patients (subjects) about personal information was strictly maintained. This was not an interventional study. The study did no hazard to environment.

\section{References}

1 Srilatha B, Hima Bindu A, Soumya D. Epidemiology and Treatment for Thyroid Cancer. J Cancer Sci Ther 2011; S17.

2 Harris PE. The management of thyroid cancer in adults: a review of new guidelines. Clinical medicine 2002; 2(2):144-146.

3 Pacini F, Castagna MG, Brilli L et al. Thyroid cancer: ESMO Clinical Practice Guidelines for diagnosis, treatment and follow-up. Annals of oncology 2010; 21(5):214-219.

4 Katoh H, Yamashita K, Enomoto T et al. Classification and general considerations of thyroid cancer. Ann Clin Pathol 2015; 3(1):1045.
5 Fagin JA and Wells Jr SA. Biologic and clinical perspectives on thyroid cancer. New England Journal of Medicine 2016;375(11):1054-1067.

6 Tuttle RM, Ball DW, Byrd D et al. Thyroid carcinoma. Journal of the National Comprehensive Cancer Network 2010; 8(11):1228-1274.

7 Morris LG, Sikora AG, Tosteson TD et al. The increasing incidence of thyroid cancer: the influence of access to care. Thyroid 2013; 23(7):885-891.

8 Rahbari R, Zhang L, Kebebew E. Thyroid cancer gender disparity; Future Oncology 2010; 6(11):17711779 .

9 Al-Zaher N, Al-Salam S, Teraifi H. Thyroid carcinoma in the United Arab Emirates: perspectives and experience of a tertiary care hospital. Hematology/ oncology and stem cell therapy 2008; 1(1):14-21.

10 Ahmadi N, Grewal A, Davidson BJ. Patterns of cervical lymph node metastases in primary and recurrent papillary thyroid cancer. Journal of oncology 2011; 2011:1-5.

11 American Cancer Society, http://www.cancer.org/ cancer/thyroid-cancer/detection-diagnosis-staging/ signs-symptoms.html

12 Hasan MN. A prescription based survey on prevalence and management of thyroid cencer. (Doctoral dissertation, East West University) 2016.

13 Wendler J, Kroiss M, Gast K et al. Clinical presentation, treatment and outcome of anaplastic thyroid carcinoma: Results of a multicenter study in Germany. European journal of endocrinology 2016; 175(6):521-529.

14 Chang CY, Lin LF, Hung YZ et al. Nuclear medicine in the evaluation of differentiated thyroid carcinoma: A clinical review. Journal of Medical Sciences 2005; 25(4):173-180.

15 Hoang JK, Lee WK, Lee M et al. US Features of thyroid malignancy: pearls and pitfalls. Radiographics 2007; 27(3):847-860.

16 DeLellis RA (ed.). Pathology and genetics of tumours of endocrine organs (Vol. 8), IARC, 2004.

17 Nikiforov YE, Biddinger PW, Thompson LD. Diagnostic surgical pathology and molecular genetics of the thyroid (p. 413), Baltimore, MD: Lippincott William and Wilkins, 2009.

18 Hofstra RM, Landsvater RM, Ceccherini I et al. A mutation in the RET proto-oncogene associated with multiple endocrine neoplasia type $2 \mathrm{~B}$ and sporadic medullary thyroid carcinoma. Nature 1994; 36(6461):375-376.

19 Choudhury,MAM and Shaikh MAA. Management of papillary and follicular (differentiated) thyroid carcinoma: an update. Bangladesh Journal of Otorhinolaryngology 2010; 16(2):126-130. 
20 Alauddin M, Joarder MAH. Management of thyroid carcinoma -an experience in Bangladesh. Indian Journal of Otolaryngology and Head and Neck Surgery 2004; 56(3):201-205.

21 Howlader N, Noone AM, Krapcho M et al. SEER Cancer Statistics Review, 1975-2008. Bethesda, MD: National Cancer Institute; 2011. Also available online Last accessed December, 1.

22 Leenhardt L, Bernier MO, Boin-Pineau MH et al. Advances in diagnostic practices affect thyroid cancer incidence in France. European Journal of Endocrinology 2004; 15(2):133-139.

23 Rahman MA, Biswas MA, Siddika ST et al. Histomorphological pattern of thyroid lesions. Dinajpur Med Col J 2013; 6:134-40.

24 Hussain F, Iqbal S, Mehmood A et al. Incidence of thyroid cancer in the Kingdom of Saudi Arabia, 20002010. Hematol Oncol Stem Cell Ther; 6(2) Second Quarter 2013:58-64.

25 Merchant D. Demographic review: clinical and histological presentation of patients with primary thyroid carcinoma presenting at tertiary care hospital. The Health 2012; 3(1):7-9.

Williams ED, Doniach I, Bjarnason O. Thyroid cancer in iodine rich area, histopathologic study. Cancer 1977; 39:215-222.

27 Rahman MM. Biochemical Status and Cytopathological Profile of Patients Presenting with Multinodular Goiter. J Medicine 2011; 12: 26-29

28 Unnikrishnan, AG and Menon, UV. Thyroid disorders in India: An epidemiological perspective. Indian journal of endocrinology and metabolism 2011; 15(2):S78-S81.

29 Karmarkar MG, Deo MG, Kochupillai N et al. Pathophysiology of Himalayan endemic goiter. Am J Clin Nutr 1974; 27: 96-103.

30 Sooch SS, Deo MG, Karmarkar MG et al. Prevention of endemic goitre with iodized salt. Natl Med J India 2001; 14:185-188.

31 Panday CS, Karmarkar MG, Kochupillai N. Recommended levels of salt iodation in India. Indian J Pediatr 1984; 51:53-54.

32 Usha Menon V, Sundaram KR, Unnikrishnan AG et al. High prevalence of undetected thyroid disorders in an iodine sufficient adult south Indian population . J Indian Med Assoc 2009: 107:72-77.

33 Marwaha RK, Tandon N, Gupta N et al. Residual goitre in the postiodization phase: Iodine status, thiocyanate exposure and autoimmunity. Clin Endocrinol (Oxf) 2003; 59:672-681.

Standard Occupational Classification (SOC) Manual, 2018. thyroid cancer: a population-based case-control study in Connecticut. J Occup Environ Med 2016; 58(3):299-305.

37 Aschebrook-Kilfoy B, Ward MH, Della Valle CT, Friesen MC 2014, Occupation and thyroid cancer. Occupational and Environmental Medicine, vol. 71, pp. 366-380

38 Lope V, Perez-Gomez B, Aragones N et al. Occupational exposure to ionizing radiation and electromagnetic fields in relation to the risk of thyroid cancer in Sweden. Scandinavian Journal of Work Environment \& Health 2006; 32:276-284.

39 Sigurdson AJ, Doody MM, Rao RS et al. Cancer incidence in the US radiologic technologists health study. Cancer 2003; 97:3080-3089.

40 Fincham SM, Ugnat AM, Hill GB et al. Canadian Cancer Registries- Is occupation a risk factor for thyroid cancer?. Journal of Occupational and Environmental Medicine 2000; 42:318-322.

41 Franceschi S, Barbone F, Bidoli E et al. Cancer Risk in Farmers - Results from A Multisite Case-Control Study in North-Eastern Italy, International Journal of Cancer 1993; 53:740-745.

42 Hanif MA. Head neck cancer in Bangladesh. The Daily Star, June 28, 2015, available at https:// www.thedailystar.net/health/disease/head-neckcancer-bangladesh-103879.

43 Al-Salamah SM, Khalid K, Bismar HA. Incidence of Differentiated Cancer in Nodular Goiter. Saudi Medical Journal 2002; 23(8):947-952.

44 Xie $\mathrm{C}$, Cox $\mathrm{P}$, Taylor $\mathrm{N}$ et al. Ultrasonography of thyroid nodules: a pictorial review. Insights Imaging 2016; 7(1):77-86.

45 Sushel C, Khanzada TW, Zulfikar I et al. Histopathological pattern of diagnosis in patients undergoing thyroid operations. Rawal Med J 2009; 34:14-16.

46 Sajid SH, Muzaffar S, Soomro IN et al. Morphological pattern and frequency of thyroid tumors. J Pak Med Assoc 1999; 49:131-133.

47 Nggada HA, Ojo OS, Adelusola KO. A histopathological analysis of thyroid diseases in Ileife, Nigeria. a review of 274 cases. Niger Postgrad Med J 2008; 15:47-51.

48 Kuijpens JL, Janssen-Heijnen ML, Lemmens VE et al. Comorbidity in newly diagnosed thyroid cancer patients: a population-based study on prevalence and the impact on treatment and survival. Clin Endocrinol (Oxf) 2006; 64(4):450-455.

49 Shaha AR1, Ferlito A, Rinaldo A. Distant metastases from thyroid and parathyroid cancer. ORL J Otorhinolaryngol Relat Spec 2001; 63(4):243-249. 